\title{
The Association of Genetic Markers and Malaria Infection in the Brazilian Western Amazonian Region
}

\author{
B Beiguelman, FP Alves, MM Moura*/**, V Engracia*/**, ACS Nunes*, MIO Heckmann*, \\ RGM Ferreira, LH Pereira da Silva*, EP Camargo, H Krieger ${ }^{+}$
}

Departamento de Parasitologia, Instituto de Ciências Biomédicas, Universidade de São Paulo, Av. Lineu Prestes 1374, 05508-900 São Paulo, SP, Brasil *Centro de Pesquisas em Doenças Tropicais, Porto Velho, RO, Brasil **Universidade Federal de Rondônia, Porto Velho, RO, Brasil

Almost all individuals (182) belonging to an Amazonian riverine population (Portuchuelo, RO, Brazil) were investigated for ascertaining data on epidemiological aspects of malaria. Thirteen genetic blood polymorphisms were investigated (ABO, MNSs, Rh, Kell, and Duffy systems, haptoglobins, hemoglobins, and the enzymes glucose-6phosphate dehydrogenase, glyoxalase, phosphoglucomutase, carbonic anhydrase, red cell acid phosphatase, and esterase D). The results indicated that the Duffy system is associated with susceptibility to malaria, as observed in other endemic areas. Moreover, suggestions also arose indicating that the EsD and Rh loci may be significantly associated with resistance to malaria. If statistical type II errors and sample stratification could be ruled out, hypotheses on the existence of a causal mechanism or an unknown closely linked locus involved in susceptibility to malaria infection may explain the present findings.

Key words: malaria - genetic markers - association studies - Western Amazonia - Rondônia - Brazil

Malaria, an infectious disease caused by an intra-cellular erythrocyte parasite (Plasmodium sp.), has significant associations with several red blood cell polymorphisms (hemoglobin, glucose-6-phosphate dehydrogenase, ABO and Duffy systems) detected in populations who are or were living under hyper-endemic conditions in the Old World (Allison 1954a,b, Vandepitte \& Delaisse 1957, Motulsky 1960, 1964, Siniscalco et al. 1961, Miller et al. 1976, Santos et al. 1983, Udomsangpetch et al. 1989, 1993, Carlson \& Wahlgren 1992, Barragan et al. 2000). The Amazon region, characterized by an hypo-endemic pattern of infection, due mainly to its low demographic index, provides an excellent field to test hypotheses on the generalization of these associations, as well as to investigate the existence of other associations due to either different mechanisms or to linkage disequilibria between genetic markers and genes involved with susceptibility/resistance to Plasmodium infection.

The present study is part of a large scientific project aimed to investigate the biological characteristics of some infectious diseases in the Western Amazon region of Brazil (Camargo et al. 1994, 1996, 1999) in which the association of some blood polymorphisms with two traits involved with the malaria infection is tested. Exception made to

Supported by Fundação de Amparo à Pesquisa do Estado de São Paulo (Fapesp), Conselho Nacional de Desenvolvimento Científico e Tecnológico (CNPq), Financiadora de Estudos e Projetos (Finep), Programa de Apoio aos Núcleos de Excelência (Pronex) and Fundação Nacional de Saúde.

${ }^{+}$Corresponding author. Fax: +55-11-3091.7417. E-mail: hkrieger@icb.usp.br

Received 4 December 2002

Accepted 14 March 2003 haptoglobin, which has an important role as hemoglobin carrier, the investigated genetic markers are red blood cell polymorphisms, since erythrocytes are the ultimate target cells of the malarial parasite.

\section{MATERIALS AND METHODS}

A blood sample was collected from each of 182 individuals, practically the whole population living in Portuchuelo, a riverine settlement in the state of Rondônia, Brazil (Figure), right bank of the Madeira river ( $8^{\circ} 37^{\prime} \mathrm{S}$, $63^{\circ} 49^{\prime} \mathrm{W}$ ) that can be reached by boat throughout the year, and also by road during the dry season (from May to September). All individuals were clinically examined, malaria being diagnosed by light microscopy and by nested polymerase chain reaction (PCR) assay. The clinical examination included a detailed anamnesis with emphasis on past exposure to malaria. The same information was given by the parents of children unable to answer satisfactorily. This research was approved by the "Medical Board of the State of Rondônia, Brazil", and an informed consent was obtained from all adults, as well as from the parents or legal guardians of minors who participated in the present study.

The community of Portuchuelo is composed by descendants of the 19th and beginning of the 20th century European settlers, with a heavy admixture with the Amerindians who lived in this part of the Madeira region. During the "rubber boom" and the construction of the Madeira-Mamoré railroad, an African contribution to the gene pool of Portuchuelo's population was brought by both the Northeastern Brazilian and Caribbean workers, particularly from Granada and Barbados, who migrated to this area. Now, this tri-hybrid population seems to be stable, and the contribution of each of its components is estimated as Amerindians $=0.44 \pm 0.64$; Caucasoids $=$ $0.35 \pm 0.069$; Africans $=0.21 \pm 0.046$ (Ferreira et al. 2002) 


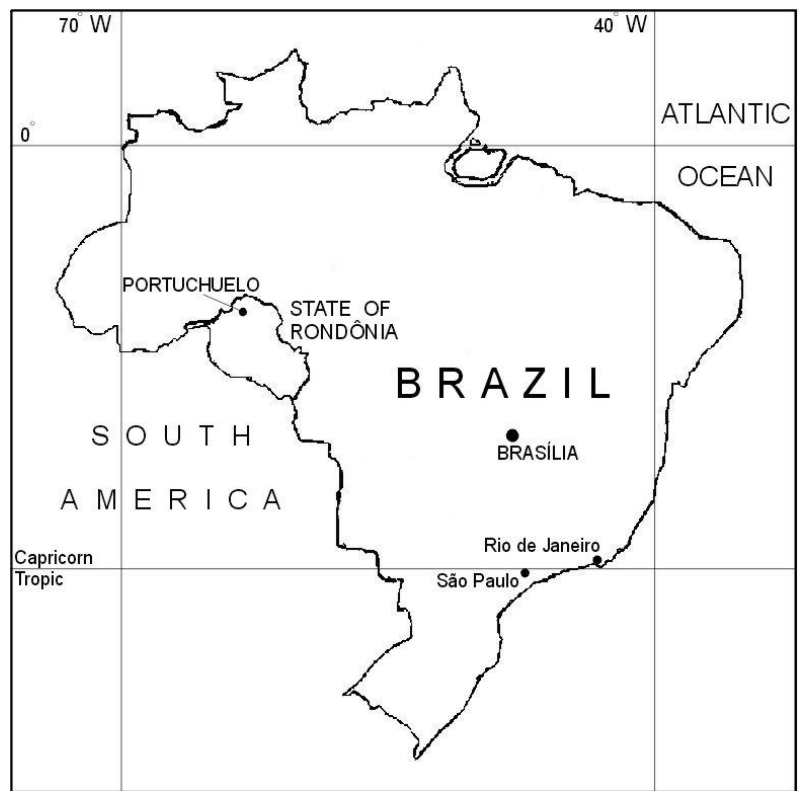

Map displaying the State of Rondônia within Brazil, and the settlement of Portuchuelo within the State of Rondônia.

The mean age of this community was 24.9 years. Since this population was represented by nuclear families the very large standard deviation observed (19.75 years) is understandable. As expected, when parents and offspring were analyzed separately, the standard deviations narrowed, notwithstanding continuing broad. Thus, the mean age of the parental generation was $47.6 \pm 16.0$ for males and $41.5 \pm 15.0$ for females, whereas for the offspring generation it was $15.5 \pm 13.6$ for males and $13.4 \pm 12.0$ for females. The sex ratio of the population was 1.04 , a value that is usually found in other Brazilian populations (Beiguelman et al. 1995).

The main occupation of the great majority of fathers is concerned with both fishing and subsistence agriculture, while the mothers are dedicated to both domestic and agricultural activities.

Two main phenotypes involved with Plasmodium infection were studied: a) the presence of symptomless infection, i.e., presence of Plasmodium vivax or Plasmodium falciparum in blood, diagnosed by the traditional thick smear and/or by PCR amplification of Plasmodium ribosomal DNA, but without malaria symptoms during a 60 days follow-up after diagnosis, regardless of the onset of the infection; b) the reported number of previous malaria episodes for life.

During the first year of this study 45 patients presented symptomatic infection. All of them were treated according to the National Health Foundation standard protocols. The annual parasite index (API) in this settlement was 385 per 1,000 inhabitants in 1999, a much higher value than the API estimated for the whole state of Rondônia in the same year (49.6 per 1,000 inhabitants). Detailed information on the malarial epidemiological data, that included prevalence of $P$. falciparum and $P$. vivax infections in the cross-sectional surveys, is presented elsewhere (Camargo et al. 1999, Alves et al. 2002).
The ABO, Rh (C, c, D, E, e antigens), MNSs (M, N, S, $\mathrm{s}$ antigens), Kell (K antigen) and Duffy ( $\mathrm{Fy}^{\mathrm{a}}$ and $\mathrm{Fy}$ b antigens) blood group systems were investigated by means of a micro-typing kit (DiaMed-ID Micro Typing System), Coombs test being used for the last two systems. Haptoglobin (Hp) typing was conducted in starch gel electrophoresis according to the classical Smithies' (1955) method. Glyoxalase (GLO1), esterase D (EsD), carbonic anhydrase (CAII), phosphoglucomutase (PGM1), glucose6-phosphate dehydrogenase (G-6-PD) and hemoglobin (Hb) were typed by starch-agarose gel electrophoresis according to the method of Wraxall and Stolorow (1978) and stained following procedures described in Harris and Hopkinson (1976). Red cell acid phosphatase (ACP1) was typed by high field strength iso-electric focusing on cellulose acetate membrane according to the method of Kane et al. (1990).

Non-parametric independence tests $(2 \times \mathrm{n}$ contingency chi-square tests for symptomless infection phenotypes and Kruskal-Wallis tests for the number of malaria episodes) were applied to the data. Since the number of malarial episodes has no normal distribution, it was taken the logarithm of each value to enable a stepwise multiple regression analysis, in which the number of malarial episodes was the dependent variable.

\section{RESULTS}

Table I shows the results of the independence chisquare $\left(\chi^{2}\right)$ tests between the ABO, MNSs, Rh, Kell, Duffy, Hb, Hp, G-6-PD, GLO, PGM1, ACP1, and EsD systems and the symptomless infection with $P$. vivax, $P$. falciparum, and the pooled infection, as well as results of the Kruskal-Wallis independence test $(\mathrm{H})$ for investigating the association between the same genetic systems and the number of malarial episodes.

In this Table it seems clear that when the independence tests were applied to the distribution of the ABO blood groups no significant associations could be detected. In contrast, a significant association between individuals with $\mathrm{A}$ or/and $\mathrm{B}$ antigens and the number of malaria episodes was observed.

In the population of Portuchuelo eight Rh phenotypes have been recognized with five $\mathrm{Rh}$ anti-sera (CCDee, CCDEe, CcDee, CcDEe, ccDee, ccDEe, ccDEE, and ccddee). No significant associations could be observed either when all these phenotypes were taken into account or when the reactions with anti-D or with anti-C and antic sera were analyzed separately. However, when the EE, $\mathrm{Ee}$, and ee phenotypes were considered, a tendency for association with the number of malarial episodes was observed. This prompted us to retest this association by analyzing only two phenotypic classes ( $\mathrm{E}_{-}$and ee phenotypes). This time a significant association could be observed $(\mathrm{H}=4.499 ; 1$ d.f.; $\mathrm{P}=0.034)$, ee phenotype individuals exhibiting a higher number of malaria episodes than phenotype E_ persons.

Similarly, no significant association was observed when the phenotypes Fy(a+b-), Fy $(a+b+), F y(a-b+)$, and Fy(ab-) of the Duffy system were tested. However, when these phenotypes except Fy(a-b-) were pooled together for the independence tests, a significant association with the 
number of malarial episodes emerged. In Table I it is also seen that the number of malarial episodes was significantly associated with the esterase D system, this association being due to a lesser number of these episodes manifested by the heterozygous phenotype (1-2) for EsD. Concerning the independence tests between the different genetic polymorphisms and the symptomless infections, only G-6PD system among females has shown a significant association with symptomless $P$. vivax infection.

As expected, age was significantly associated with the number of malarial episodes (Table II), the lower age groups exhibiting lower mean ranks of the number of malarial episodes than the higher age groups $(\mathrm{H}=31.418$; D.F. $=9 ; \mathrm{P}<0.001)$. Since the observed associations with the number of malarial episodes could be an effect of age, the mean rank of ages of the sample grouped as: either $\mathrm{O}$ or with $\mathrm{A}$ or/and $\mathrm{B}$ antigens; $\mathrm{E}$ _ and ee phenotypes; Fy(ab-) and non-Fy(a-b-) groups; as well as EsD phenotypes (1-1, 1-2, 2-2) were compared by applying a Kruskal-Wallis test to all cases. The results obtained enabled to reject the hypothesis that age could have influenced the observed association between the number of malarial episodes with $\mathrm{E}$ and ee phenotypes $(\mathrm{H}=0.299 ; 1$ D.F.; $\mathrm{P}=$ $0.585)$, the Duffy system $(\mathrm{H}=3.362$; D.F.; $\mathrm{P}=0.067)$ or with $\operatorname{EsD}(H=0.926 ; D . F .=2 ; P=0.629)$. The same was not true for the $\mathrm{ABO}$ system, since the mean rank of age of the group $\mathrm{O}$ subjects was significantly lower than that of individuals with $\mathrm{A}$ and/or $\mathrm{B}$ antigens $(\mathrm{H}=8.001$; D.F. $=1$;
$\mathrm{P}=0.005)$. Curiously, this phenomenon was confirmed in the offspring generation $(\mathrm{H}=5.657 ;$ D.F. $=1 ; \mathrm{P}=0.017)$ but not among the parents $(\mathrm{H}=0.446$; D.F. $=1 ; \mathrm{P}=0.504)$.

Taking into account these results, the influence of several independent variables [age, squared age, sex (coded as zero for females and 1 for males), age $\times$ sex, squared age $\times$ sex, and $\mathrm{ABO}$ system grouped as $\mathrm{O}$ (coded as zero) and with $\mathrm{A}$ or/and $\mathrm{B}$ antigens (coded as 1)] on the

\section{TABLE II}

Distribution of the mean number of malarial episodes according to age groups, and Kruskal-Wallis test to investigate the association of age groups with the number of malarial episodes (mean ranks)

\begin{tabular}{lrcc}
\hline $\begin{array}{l}\text { Age groups } \\
\text { (years) }\end{array}$ & $\mathrm{Nr}$ & $\begin{array}{c}\text { Mean number } \\
\text { of malarial } \\
\text { episodes }\end{array}$ & Mean rank \\
\hline$<5$ & 24 & $1.25 \pm 1.85$ & 44.69 \\
$5-10$ & 28 & $3.04 \pm 2.43$ & 83.38 \\
$10-15$ & 28 & $3.68 \pm 4.20$ & 84.69 \\
$15-20$ & 19 & $5.21 \pm 3.68$ & 108.08 \\
$20-25$ & 15 & $5.27 \pm 5.32$ & 97.97 \\
$25-30$ & 9 & $10.22 \pm 15.59$ & 112.33 \\
$30-35$ & 6 & $9.00 \pm 9.70$ & 109.75 \\
$35-40$ & 7 & $5.00 \pm 7.44$ & 78.21 \\
$40-45$ & 6 & $8.00 \pm 15.71$ & 80.33 \\
$\geq 45$ & 37 & $10.03 \pm 16.82$ & 110.86 \\
\hline
\end{tabular}

H: 31.418; D.F.: 9; $\mathrm{P}<0.001$

TABLE I

Results of the independence tests between different genetic systems and symptomless infection and number of malarial episodes

\begin{tabular}{|c|c|c|c|c|c|}
\hline \multirow{3}{*}{ Phenotypes } & \multirow{3}{*}{$\begin{array}{l}\text { Degrees } \\
\text { of } \\
\text { freedom }\end{array}$} & \multicolumn{3}{|c|}{ Symptomless infection } & \multirow{2}{*}{$\begin{array}{c}\mathrm{Nr} \text { of } \\
\text { malarial } \\
\text { episodes }\end{array}$} \\
\hline & & Plasmodium vivax & P. falciparum & Total & \\
\hline & & $\chi^{2} ; \mathrm{P}$ & $\chi^{2} ; \mathrm{P}$ & $\chi^{2} ; \mathrm{P}$ & $\mathrm{H} ; \mathrm{P}$ \\
\hline $\mathrm{ABO}$ & 3 & $0.352 ; 0.996$ & $0.400 ; 0.940$ & $0.523 ; 0.914$ & $4.589 ; 0.204$ \\
\hline $\mathrm{A}+\mathrm{B}+\mathrm{AB}$ & 1 & $0.003 ; 0.953$ & $0.003 ; 0.953$ & $0.044 ; 0.833$ & $4.054 ; 0.044$ \\
\hline $\mathrm{B}+\mathrm{AB}$ & 1 & $0.001 ; 0.980$ & $0.261 ; 0.609$ & $0.065 ; 0.800$ & $2.933 ; 0.087$ \\
\hline MNSs & 8 & $8.583 ; 0.379$ & $5.813 ; 0.668$ & $5.048 ; 0.752$ & $5.684 ; 0.683$ \\
\hline $\mathrm{MM}, \mathrm{MN}, \mathrm{NN}$ & 2 & $0.655 ; 0.721$ & $0.012 ; 0.994$ & $0.348 ; 0.840$ & $1.036 ; 0.596$ \\
\hline $\mathrm{SS}, \mathrm{Ss}, \mathrm{sS}$ & 2 & $1.248 ; 0.536$ & $4.233 ; 0.120$ & $1.187 ; 0.552$ & $2.836 ; 0.242$ \\
\hline $\mathrm{Rh}$ & 7 & $5.616 ; 0.585$ & $8.943 ; 0.257$ & $3.151 ; 0.871$ & $7.273 ; 0.401$ \\
\hline $\mathrm{CC}, \mathrm{Cc}, \mathrm{cc}$ & 2 & $0.719 ; 0.698$ & $1.050 ; 0.592$ & $0.216 ; 0.898$ & $1.843 ; 0.398$ \\
\hline $\mathrm{D}, \mathrm{dd}$ & 1 & $1.341 ; 0.247$ & $0.355 ; 0.551$ & $0.310 ; 0.578$ & $0.472 ; 0.492$ \\
\hline $\mathrm{E} \overline{\mathrm{E}}, \mathrm{Ee}$, ee & 2 & $1.625 ; 0.444$ & $0.988 ; 0.610$ & $1.953 ; 0.377$ & $5.713 ; 0.057$ \\
\hline E_, ee & 1 & $0.621 ; 0.431$ & $0.174 ; 0.676$ & $0.060 ; 0.807$ & $4.499 ; 0.034$ \\
\hline Këll & 1 & $1.518 ; 0.218$ & $0.219 ; 0.640$ & $0.488 ; 0.485$ & $0.886 ; 0.347$ \\
\hline Duffy & 3 & $1.255 ; 0.740$ & $0.800 ; 0.849$ & $1.719 ; 0.633$ & $5.043 ; 0.169$ \\
\hline Fy(a-b-) & 1 & $0.001 ; 0.970$ & $0.551 ; 0.456$ & $0.315 ; 0.575$ & $4.632 ; 0.031$ \\
\hline $\mathrm{Hp}$ & 3 & $2.120 ; 0.548$ & $2.141 ; 0.544$ & $0.365 ; 0.947$ & $1.104 ; 0.776$ \\
\hline Нp 1-1 & 1 & $0.726 ; 0.394$ & $1.526 ; 0.217$ & $0.090 ; 0.764$ & $0.499 ; 0.480$ \\
\hline $\mathrm{Hb}$ & 1 & $0.040 ; 0.841$ & $0.483 ; 0.487$ & $0.052 ; 0.820$ & $0.202 ; 0.653$ \\
\hline G-6-PD, Males & 2 & $4.195 ; 0.123$ & $1.029 ; 0.598$ & $1.240 ; 0.538$ & $1.182 ; 0.554$ \\
\hline G-6-PD, Females & 1 & $4.353 ; 0.037$ & $0.064 ; 0.801$ & $2.721 ; 0.099$ & $0.323 ; 0.570$ \\
\hline GLO & 2 & $4.263 ; 0.119$ & $2.018 ; 0.365$ & $3.530 ; 0.171$ & $0.825 ; 0.662$ \\
\hline PGM1 & 2 & $3.944 ; 0.139$ & $0.029 ; 0.985$ & $4.002 ; 0.135$ & $0.473 ; 0.790$ \\
\hline $\mathrm{ACP} 1$ & 4 & $4.849 ; 0.303$ & $7.123 ; 0.129$ & $8.617 ; 0.071$ & $4.342 ; 0.362$ \\
\hline EsD & 2 & $0.660 ; 0.719$ & $4.240 ; 0.120$ & $0.784 ; 0.676$ & $6.840 ; 0.033$ \\
\hline
\end{tabular}

$\chi^{2}$ : results of the independence chi-square test; H: results of the independence Kruskal-Wallis test; P: probability 
logarithm of the number of malarial episodes (dependent variable) were analyzed by stepwise multiple regression. This analysis enabled to see that, exception made to the product of squared age $\times$ sex, all other variables have not influenced significantly the number of malarial episodes. Since the females were coded as zero and the partial regression coefficient of squared age $\times$ sex on the dependent variable was positive (3.702 with a standard error of $0.834 ; \mathrm{t}=4.437 ; \mathrm{P}<0.001)$, this result also indicates that the influence of age is restricted to the males.

\section{DISCUSSION}

It is known that parasitized erythrocytes form rosettes more readily with red blood cells of either $\mathrm{A}, \mathrm{B}$ or $\mathrm{AB}$ groups than with those belonging to blood group $\mathrm{O}$ (Udomsangpetch et al. 1989,1993, Carlson \& Wahlgren 1992, Barragan et al. 2000), and that, in Zimbawe, blood group A was associated with both lower hemoglobin levels and severe central nervous system malaria with coma (Fisher \& Boone 1998). In spite of the fact that these phenomena might provoke an association of $\mathrm{ABO}$ blood groups and the number of malarial episodes, the results presented above do not enable to reject the null hypothesis that this polymorphic system is not associated with the number of malarial episodes. The absence of association between $\mathrm{ABO}$ system and malaria infection was also observed in other populations (Osisanyia 1983, Singh et al. 1986, 1995, Bayoumi et al. 1986, Montoya et al. 1994) but Santos et al. (1983) detected in Brazil a significant association between the presence of $\mathrm{B}$ antigen and the number of malarial episodes. Although our results pointed to the same direction, we were not able to confirm this observation by combining the frequency of $\mathrm{B}$ and $\mathrm{AB}$ individuals. However, it should be mentioned that, agreeing with Santos' et al. (1983) data, performing a preliminary analysis on another sample (Camargo et al., in preparation) we were able to detect an association between the number of malarial episodes and the presence of B antigen among 873 individuals living in Monte Negro, a rural area of the same State of Rondônia $\left(10^{\circ} 15^{\prime} \mathrm{S}, 63^{\circ} 18^{\prime} \mathrm{W}\right)$, the Kruskal-Wallis test resulting in $\mathrm{H}=4.114 ; 1$ d.f.; $\mathrm{P}=$ 0.043 .

The genetic polymorphism of glycophorin plays an important role in the resistance to the invasion of erythrocytes by P. falciparum (Pasvol et al. 1982, Hadley et al. 1986). Since long it is known that sialic acid is an essential part of the $\mathrm{M}, \mathrm{N}$ receptors and that the receptive capacity of glycophorin depends on sialic acid, which is an essential part of the $\mathrm{M}, \mathrm{N}$ receptors, one might suppose that MNSs system could be associated in some way with malaria infection (Mäkelä \& Cantell 1958). However, as it is seen in Table I, no significant associations could be observed either when the nine phenotypes observed were taken into account (MMSS, MMSs, MMss, MNSS, MNSs, MNss, NNSS, NNSs, and NNss) or when the reactions with anti-M, anti-N and anti-S, anti-s were analyzed separately. This result is in disagreement with that of Montoya et al. (1994), who observed in Colombia that the MNSs system confers resistance to both species of Plasmodium. Nevertheless, it should be stressed that the proportion of individuals who were negative to both anti-M and anti-N among the Negroids studied by Montoya et al. (1994) was conspicuously high $(7.8 \%)$.

Concerning the $\mathrm{Rh}$ system, it is curious that in another population of the state of Rondônia, living in Monte Negro (Camargo et al., in preparation), it was observed that the E_phenotype individuals exhibited a higher number of malarial episodes than ee phenotype persons, the Kruskal-Wallis test resulting in a highly significant value $(H=12.324 ; 1$ d.f.; $P \cong 0)$. Since this result is completely opposite to that observed in the present population, the association of the number of malarial episodes with $\mathrm{E}$ or ee phenotypes might be taken as fortuitous, although it is attractive to speculate whether the $\mathrm{Rh}$ locus might be closely linked to a gene involved in susceptibility to malaria infection, being the observed significant deviations due to different phases of linkage disequilibrium.

Kell system did not exhibit association with the phenotypes involved in Plasmodium infection, a result that was also observed in other populations (Singh et al. 1986, Bayoumi et al. 1986, Montoya et al. 1994).

The lesser mean number of malarial episodes in Fy(ab-) individuals as compared to other positive Duffy phenotypes may obviously be considered as a consequence of the well-known resistance to $P$. vivax infection manifested by individuals whose red blood cells do not react with both anti-Fy and anti-Fy ${ }^{\mathrm{b}}$ antisera (Miller et al. 1976, Wertheimer \& Barnwell 1989). Concerning the individuals with symptomless $P$. vivax infection who exhibit Duffy negative phenotype it may be said that their number is too small to allow any statistically valid interpretation.

Harrison et al. (1976), in spite of not finding an association between haptoglobin and the presence of malaria parasites in blood, claimed to have strong evidence that, in New Guinea, homozygotes for $\mathrm{Hp}_{1}$ gene are more likely to show signs of hepatomegaly and splenomegaly than $\mathrm{Hp}_{1} \mathrm{Hp}$, heterozygotes. Santos et al. (1983) and Singh et al. (1986) found a significant excess of individuals with the Hp1-1 phenotype among malaria patients in Brazil and in India, respectively. In our data haptoglobin did not show significant association with the phenotypes involved in Plasmodium infection neither when all detected phenotypes (Hp1-1, Hp1-2, Hp 2-2, Hp1-2M) were considered nor when all of them except Hp1-1 were pooled together. Supporting the present results, no association between haptoglobin phenotypes and P. falciparum infection was also observed by Bayoumi et al. (1986) in Sudan.

Since long it is known that sickle cell trait affords protection against $P$. falciparum infection (Allison 1954a,b Vandepitte \& Delaisse 1957). In our data no significant association between AS genotype and the phenotypes involved in Plasmodium infection could be detected due to both a relatively low proportion of P. falciparum infection $(30 \%)$ among the malarial cases and a small frequency of AS individuals in Portuchuelo (3\%).

The relative protection of G-6-PD deficiency against P. falciparum postulated by Motulsky (1960) is manifested by the heterozygous females but not by the males who are hemizygous for the deficient gene (Bienzle et al. 1972, Usanga \& Luzzato 1985). Therefore, the absence of association between G-6-PD among males and the phenotypes 
involved in Plasmodium infection seen in Table I, as well as the significant association of the females symptomless for $P$. vivax with homozygosis for the gene $G d^{B}$ has no practical meaning.

The distribution of GLO phenotypes (1-1, 1-2, and 2-2) was independent from the phenotypes involved with Plasmodium infection, a result that agrees with that observed by Bayoumi et al. (1986) in Sudan. Regarding PGM1 system, these authors found a significant excess of the 1-1 phenotype among malaria patients, but such association could not be demonstrated in Portuchuelo. No statistical tests were performed concerning CA2, since all individuals except one (phenotype 1-2) exhibited phenotype 1-1.

Bottini et al. (1972) have suggested a possible disadvantage of the allele $\mathrm{ACP} 1{ }^{*} \mathrm{C}$ in areas characterized in the past by high malaria endemicity (Mediterranean area), while other authors indicated that the ACP $1 *$ R allele could have this disadvantage in Africa (Spedini et al. 1980). In Portuchuelo, as in African populations where malaria is endemic (Destro-Bisol et al. 1992), the ACP $1 *$ R allele was not found while the five ACP1 observed phenotypes (A, $\mathrm{AB}, \mathrm{AC}, \mathrm{B}$, and $\mathrm{BC}$ ) showed no association with the phenotypes involved with Plasmodium infection.

A result that should be confirmed in other populations, since it is here referred for the first time, is the observed significant association between the number of malarial episodes and EsD. The caution to associate a particular genetic system with a disease stems from the fact that statistic type II error, sample non-randomness, and stratification are common factors that mimic genetic associations. Also it should be stressed that the authors could not find an easy explanation for the correlation of the number of malarial episodes with age being restricted to males.

Finally, it should be emphasized that the authors are aware on the difficulty that people living in an endemic area have to remind the exact number of malarial episodes. However, it should be reminded that this difficulty has been somewhat circumvented when both the logarithm of the number of malarial episodes and the rank of the number rather than the number itself were used, since these transformations minimize small distortions of the informed values.

\section{REFERENCES}

Allison AC 1954a. Protection afforded by sickle-cell trait against subtertian malarial infection. Brit Med J 1: 290-294.

Allison AC 1954b. The distribution of sickle-cell trait in East Africa and elsewhere and its apparent relationship to the incidence of subtertian malaria. Trans $R$ Soc Trop Med Hyg 48: 312-318.

Alves FP, Durlacher RR, Menezes MJ, Krieger H, Pereira da Silva LH, Camargo EP 2002. High prevalence of asymptomatic Plasmodium vivax and Plasmodium falciparum infections in native Amazonian populations. Am J Trop Med Hyg 66: 641-648.

Barragan A, Kremsner PG, Wahlgren M, Carlson J 2000. Blood group A antigen is a coreceptor in Plasmodium falciparum rosetting. Infect Immun 68: 2971-2975.

Bayoumi RA, Bashir AH, Abdulhadi NH 1986. Resistance to falciparum malaria among adults in central Sudan. Am J Trop Med Hyg 35: 45-55.
Beiguelman B, Franchi-Pinto C, Dal Colletto GMD, Krieger H 1995. Annual variation of sex ratio in twin births and in singletons in Brazil. Acta Genet Med Gemell 44: 159-164.

Bienzle U, Ayeni O, Lucas AO, Luzzato L 1972. Glucose-6phosphate dehydrogenase and malaria. Greater resistance of females heterozygous for enzyme deficiency and of males with non deficient variant. Lancet 1: 107-110.

Bottini E, Lucarelli P, Bastianon V, Gloria F 1972. Erythrocyte acid phosphatase and hemolysis. J Med Genet 9: 434-435.

Camargo LMA, Dal Colleto GMD, Ferreira MU, Gurgel SM, Escobar AL, Marques A, Krieger H, Camargo EP, Pereira da Silva LH 1996. Hypoendemic malaria in Rondônia (Brazil, Western Amazon region): seasonal variation and risk groups in an urban locality. Am J Trop Med Hyg 55: 32-38.

Camargo LMA, Ferreira MU, Krieger H, Camargo EP, Pereira da Silva LH 1994. Unstable hypoendemic malaria in Rondônia (Western Amazon region, Brazil): epidemic outbreaks and work-associated incidence in agro-industrial rural settlement. Am J Trop Med Hyg 51: 16-25.

Camargo LMA, Noronha E, Salcedo JMV, Dutra AP, Krieger H, Pereira da Silva LH, Camargo EP 1999. The epidemiology of malaria in Rondônia (Western Amazon region, Brazil): study of a riverine population. Acta Trop 72: 1-11.

Carlson J, Wahlgren M 1992. Plasmodium falciparum erythrocyte rosetting is mediated by promiscuous lectin-like interactions. J Exp Med 176: 1311-1317.

Destro-Bisol G, Battaggia C, Macchiarelli R, Bailly C, Scozzani MR, Spedini G 1992. A bio-anthropological study on the Bakakas of Cameroon. Ann Hum Biol 19: 185-195.

Ferreira RGM, Moura MM, Engracia V, Pagotto RC, Alves FP, Camargo LM, Pereira da Silva LH, Camargo EP, Beiguelman B, Krieger H 2002. Ethnic admixture composition of two western Amazonian populations. Hum Biol 74: 607-613.

Fisher PR, Boone P 1998. Severe malaria associated with blood group. Am J Trop Med Hyg 58: 122-123.

Hadley TJ, Erkmen Z, Kaufman BM, Futrovsky S, McGinnis MH, Graves P, Sadoff JC, Miller LH 1986. Factors influencing invasion of erythrocytes by Plasmodium falciparum parasites: the effects of an N-acetyl glucosamine neoglycoprotein and an anti-glycophorin A antibody. Am J Trop Med Hyg 35: 898-905.

Harris H, Hopkinson DA 1976. Handbook of Enzyme Electrophoresis in Human Genetics, North Holland Publ. Co., Amsterdam, $374 \mathrm{pp}$.

Harrison GA, Boyce AJ, Hornabrook RW, Craig WJ 1976. Associations between polymorphic variety and disease susceptibility in two New Guinea populations. Ann Hum Biol 4: 253-267.

Kane M, Yamamoto Y, Yamada M, Fukunaga T, Tatsuno Y 1990. Phenotyping of erythrocyte acid phosphatase and esterase D by high field strength isoelectric focusing on cellulose acetate membrane. Electrophoresis 2:318-321.

Mäkelä O, Cantell K 1958. Destruction of M and N blood group receptors of human red cells by some influenza viruses. Ann Med Exp Fenn 36: 366-374.

Miller LH, Mason SJ, Clyde DF, McGinniss MH 1976. The resistance factor to Plasmodium vivax in Blacks. The Duffy blood-group genotype FyFy. N Engl J Med 295: 302-304.

Montoya F, Restrepo M, Montoya AE, Rojas W 1994. Blood groups and malaria. Rev Inst Med Trop São Paulo 36: 3338.

Motulsky AG 1960. Metabolic polymorphisms and the role of infectious diseases in human evolution. Hum Biol 132: 2862.

Motulsky AG 1964. Hereditary red cell traits and malaria. Am J Trop Med Hyg 13: 147-158. 
Osisanyia JO 1983. ABO blood groups and infections with human malarial parasites in vivo and in vitro. East Afr Med J 60: 616-621.

Pasvol G, Wainscoat JS, Weatherall DJ 1982. Erythrocytes deficiency in glycophorin resist invasion by the malarial parasite Plasmodium falciparum. Nature 297: 64-66.

Santos SEB, Salzano FM, Franco MHLP, Freitas MJM 1983. Mobility, genetic markers, susceptibility to malaria and race mixture in Manaus, Brazil. J Hum Evol 12: 373-381.

Singh IP, Walter H, Bhasin MK, Veena B, Sudhakar K 1986. Genetic markers and malaria. Observations in Gujarat, India. Hum Hered 36: 31-36.

Singh N, Shukla MM, Uniyal VP, Sharma VP 1995. ABO blood groups among malaria cases from District Mandla, Madhya Pradesh. Indian J Malariol 32: 59-63.

Siniscalco M, Bernini L, Latte B, Motulsky AG 1961. Favism and thalassemia in Sardinia and their relationship to malaria. Nature 190: 1170-1180.

Smithies O 1955. Zone electrophoresis in starch gels: group variation in serum proteins of normal human adults. Bioch $J$ 61: 629-631.

Spedini G, Capucci E, Fuciarelli M, Rickards O 1980. The AcP polymorphisms frequencies in the Mbugu and Sango of
Central Africa (correlations between the $\mathrm{P} * \mathrm{r}$ allele and some climatic factors in Africa). Ann Hum Biol 7: 125-128.

Udomsangpetch R, Todd J, Carlson J, Greenwood BM 1993. The effects of hemoglobin genotype and ABO blood group on the formation of rosettes by Plasmodium falciparuminfected red blood cells. Am J Trop Med Hyg 48: 149-153.

Udomsangpetch R, Wählin B, Carlson J, Berzins K, Torii M, Aikawa M, Perlmann P, Wahlgren M 1989. Plasmodium falciparum-infected erythrocytes form spontaneous erythrocyte rosettes. J Exp Med 169: 1835-1840.

Usanga EA, Luzzato L 1985. Adaptation of Plasmodium falciparum to glucose-6-phosphate dehydrogenase-deficient host red cells by production of parasite-encoded enzyme. Nature 313: 793-795.

Vandepitte J, Delaisse J 1957. Sicklemie et paludisme. Ann Soc Belge Med Trop 3: 703-735.

Wertheimer SP, Barnwell JW 1989. Plasmodium vivax interaction with the human Duffy blood group glycoprotein: identification of a parasite receptor-like protein. Exp Parasitol 69: 340-350.

Wraxall BG, Stollorow MD 1978. The simultaneous separation of the enzymes glyoxalase I, esterase D, phosphoglucomutase. Forensic Sci 31: 1439-1441. 